\title{
What is the actual cost of providing the intrauterine system for contraception in a UK community sexual and reproductive health setting?
}

\author{
Louise Cook, ${ }^{1}$ Charlotte Fleming ${ }^{2}$
}

\begin{abstract}
${ }^{1}$ Associate Specialist, Aneurin Bevan Health Board - Sexual and Reproductive Healthcare, Llanfrechfa Grange Hospital, Gwent, UK

${ }^{2}$ Consultant, Sexual and Reproductive Health, Aneurin Bevan Health Board - Sexual and Reproductive Healthcare, Llanfrechfa Grange Hospital, Gwent, UK
\end{abstract}

\section{Correspondence to Dr Louise Cook, Aneurin Bevan Health Board - Sexual and Reproductive Healthcare, Llanyrafon House, Llanfrechfa Grange, Torfaen, Cwmbran NP44 8YN, UK; Louise_cook@yahoo.com}

Received 27 April 2012 Revised 22 February 2013 Accepted 28 February 2013 Published Online First 27 April 2013

\footnotetext{
To cite: Cook L, Fleming C. J Fam Plann Reprod Health Care 2014:40:46-53.
}

\begin{abstract}
Background The anticipated increase in uptake of intrauterine system (IUS) fittings is slower than predicted by the National Institute for Health and Clinical Excellence (NICE). There is evidence to suggest that this is because of a high perceived cost of providing this contraceptive method. Whereas studies to date have all guessed at these costs, we calculated the actual costs of providing the IUS.
\end{abstract}

Methods We tracked the notes of 283 women who had an IUS fitted in our community sexual and reproductive health service for 5 years. We recorded duration of use, measured the actual cost of all appointments and interventions over the lifespan of the device, and compared our findings with NICE predicted costs.

Results With 70\% complete follow-up, the average duration of use of the IUS was 3.44 years compared to NICE's prediction of 3.32. The average annual cost of providing an IUS for contraception in community clinics was f54.55 per woman; this compares with $£ 70.49$ modelled by NICE for provision in primary care. Most $(80 \%)$ of the cost is incurred in the first year. The cost of managing problems is small. Conclusions Providing the IUS for contraception was $23 \%$ cheaper in the present study than that predicted by NICE and cheaper than providing combined oral contraception in our service. Fitting IUSs in community clinics may be cheaper than in primary care. Streamlining the patient pathway will reduce costs further. Restricting access to the IUS because of initial cost is a false economy.

\section{AIM}

The aim of the study was to establish the actual cost of providing the intrauterine

\section{Key message points}

- The cost of providing the intrauterine system (IUS) in community services is $23 \%$ lower than that estimated by the National Institute for Health and Clinical Excellence, even when the cost of ongoing care is included in the calculation.

- Streamlining services will reduce the cost of IUS provision further.

- Restricting access to the IUS on the grounds of cost is a false economy.

system (IUS) for contraception in a community sexual and reproductive health (SRH) setting in Wales, UK and compare it to that predicted by the National Institute for Health and Clinical Excellence (NICE).

\section{INTRODUCTION}

Compared with no use, contraceptive use of any method results in substantial cost savings. ${ }^{1-3}$ Many studies, both in Europe and the USA, report the IUS to be one of the most cost-effective methods of contraception. As well as being a highly effective and acceptable long-acting reversible contraception (LARC) method, the IUS also has non-contraceptive benefits. ${ }^{1-6}$

The UK's Office for National Statistics reported in 2003 that $0.7 \%$ of women aged 16-49 years used the IUS for contraception, ${ }^{7}$ and using research commissioned by the $\mathrm{fpa}^{8}$ (Family Planning Association), NICE predicted that, if fully informed, 
$4.4 \%$ of women would choose this method. In 2004, NICE modelled the theoretical cost of providing LARCs to all women and predicted huge savings to the UK National Health Service (NHS) by increasing the uptake of LARCs at the expense of oral contraception. ${ }^{7}$ They produced national guidelines promoting the use of LARC for all women, with the IUS ranked second to the implant as the most effective method. ${ }^{9}$ Increasing the uptake of LARC was identified as a government priority in England and Wales to help reduce the incidence of teenage pregnancy and abortion. ${ }^{10-12}$ By 2010, NICE reported that from 2004 to 2010 the number of prescriptions for the IUS had doubled but suggested that the uptake of LARC methods would take longer than initially predicted. ${ }^{13}$

In 2007, NICE identified a large variation in the prescribing of the IUS in community settings that was not likely to be accounted for by differences in population and choice of contraception. ${ }^{14}$ Kishen and Belfield ${ }^{15}$ reported that some services limit the availability of the IUS because of a perceived high cost of providing it. A lack of funding is often seen as a barrier to the implementation of NICE guidance. Recent financial pressures, coupled with the drive to make efficiency savings within the NHS, may be making organisations even more reluctant to fund the increase in LARC suggested by NICE guidance, guarding against overspend of budgets, especially on prescribing.

All studies to date have estimated or modelled the costs of providing the IUS for contraception, but none have confirmed the accuracy of these predictions. This article fills that gap by following women who had an IUS fitted in a single community service in Wales and measuring the actual cost of all appointments and interventions over the lifespan of the device.

In addition, although one large UK general practice study ${ }^{16}$ estimated costs of provision in primary care, there have been no studies based in community clinics that fit approximately 50\% of intrauterine contraceptive devices in Wales ${ }^{17}$ and $32 \%$ of devices in England. ${ }^{18}$ NICE suggested that costs would be lower where services are provided by family planning clinics because of economies of scale and different methods of remuneration. ${ }^{7}$ Costs of general practice provision need to be compared against those in community sexual health services to ensure value for money for the NHS.

During 2004, the SRH service in Gwent Healthcare NHS Trust, now Aneurin Bevan Health Board (ABHB), provided unrestricted, appointment-free access to the IUS through 50 clinics each week at 31 sites where staff work to a uniform protocol for IUS fitting across the service. A total of 283 women were followed for 5 years after they had had an IUS fitted in order to establish the actual costs of providing the IUS in a Welsh community SRH setting and to compare the costs with those predicted by NICE.

\section{METHODS}

We undertook a prospective cohort review of all women having an IUS fitted for contraception in our department during 2004. We looked at the visits where the patient requested an IUS, had it fitted, came back for check-ups or problems and finally had it removed. We also looked at visits where the patient was referred on because of complications relating directly to the IUS. For each visit we noted who the patient saw and what was done or prescribed. Case notes were traced and reviewed annually. In accordance with Gwent Healthcare NHS Trust policy, which was in place at the time the review commenced, formal ethical approval was not required for the study.

The study continued until either the woman stopped using an IUS, was lost to follow-up or to the end of 5 years (60 months).

Our cost analysis (in British pounds sterling, $£$ ) was based on NICE's costs in their cost impact report ${ }^{7}$ in order to enable comparisons to be made. However, we also included costs of consultations for problems after the device was fitted, which NICE did not. We included the following costs: staff time (medical and nursing), cost of the IUS, insertion and removal equipment, analgesia, chlamydia tests, drugs for side effects and management of problems. If a device was replaced early we included all associated costs. The 2012 prices are included for comparison. Costs of drugs and equipment were obtained from $\mathrm{ABHB}$ pharmacy department.

For IUSs fitted in our open-access community SRH clinics we calculated medical staff costs by the minute by assuming the highest scale point for all staff. Out of 50 open-access clinics per week, 47 had a staff grade doctor present and three had a consultant, so we calculated a theoretical salary whereby $47 / 50$ ths was staff grade pay and 3/50ths was consultant pay. We divided this by 52 to get a weekly cost, by 40 to get an hourly cost and then divided by 60 to get a cost per minute. A full-time non-consultant career grade doctor (NCCD) contract in Wales is 40 hours per week. We repeated this process to calculate nurse costs. A doctor always fitted the IUS and a Band 6 nurse was always present under protocol. The mean duration of a consultation or IUS fitting was known from an in-service review in our department, which mapped the patient pathway through clinic ('Mapping the Patient Pathway', unpublished data, Gwent Sexual and Reproductive Health, 2006).

A small number of IUSs were fitted in booked consultant community gynaecology clinics. To calculate the medical costs for this we took the whole time equivalent consultant salary, divided it by 52 to get a weekly cost, then by 10 to get the cost of a session and then by eight, as eight patients are booked per session.

The cost of IUS removal in general practice and all secondary care costs were calculated using England's 
Payment by Results National Tariff ${ }^{19}{ }^{20}$ as local or Welsh costs for these were unknown.

Where an IUS was removed at the time of a gynaecological procedure and then replaced we included the full cost of a new device. Where a device was replaced early within the community SRH clinic we included the mean cost of fitting a device. We calculated the mean cost from the total cost of fitting a device within the service divided by 283 , the number of devices fitted.

Two cohorts emerged, namely those for whom we had complete follow-up from insertion to removal (complete data) and those who disappeared from follow-up before the IUS was removed (incomplete data). For each year of the survey and for each cohort we multiplied the number of patients by the number and cost of events relating to their IUS use. Thus we obtained an actual, yearly, mean cost per patient for IUS use for each cohort and for the two together.

We calculated the mean duration of use of the IUS in the same way as this was calculated by NICE, ${ }^{7}$ using the complete data set thus: for each year we added the number of patients with the device in place at the beginning and end of the year and halved it. We added these five figures and divided by 197 (the number of the women having the device fitted).

Likewise the costs we used for direct comparison to NICE were derived from data relating only to the cohort with complete follow-up. NICE costs were taken from their cost impact report. ${ }^{7}$

We also included community training costs. In 2004, all doctors working within ABHB SRH service held as a minimum the Diploma of the Faculty of Family Planning (DFFP), now referred to as the Diploma of the Faculty of Sexual \& Reproductive Healthcare (DFSRH). They were also all trained to fit intrauterine devices (IUDs) and held the Letter of Competence in Intrauterine Techniques (LoC IUT). No staff training costs were therefore incurred. However, external trainees attended clinics as part of their practical training for LoC IUT, six devices being fitted by trainees under supervision. When training, it is anticipated that instructing doctors work below their usual capacity. $\mathrm{NICE}^{7}$ estimated this as at $50 \%$ of normal capacity and so we therefore did the same. Training costs were shared by the total cohort.

\section{RESULTS}

In 2004, according to our database 283 women had an IUS fitted and $273(96 \%)$ case notes were identified. Complete follow-up data to 5 years (60 months) was available for 197 (70\%) women. No follow-up data after the initial insertion were available for 31 (11\%) women. A further 55 (19\%) women were lost to follow-up over the subsequent 5 years $(3 \%$ at end Year 1, 1\% at end Year 2, 7\% at end Year 3, 5\% at end Year 4 and 3\% at end Year 5). In total, data relating to 10273 months of use of the IUS was available.

There were no pregnancies recorded due to failure of the device, but one pregnancy was dated to preinsertion. The costs of this pregnancy were not included in calculations as this was not an IUS-related failure.

\section{Duration of use}

Figure 1 illustrates the continuation rates for our patients for whom we had complete follow-up data, with those predicted by NICE for comparison. At 5 years (60 months), 82 (42\%) of the original 197 devices were still in situ. Continuation rates were 166 $(84 \%)$ at 1 year, $141(72 \%)$ at 2 years, $125(63 \%)$ at 3 years, $107(54 \%)$ at 4 years and $82(42 \%)$ at 5 years (Figure 1). In addition, 30 (15\%) devices were replaced early so $112 / 197$ (57\%) women were still using the IUS for contraception at 5 years. The mean duration of use of the original IUS device fitted was 3.44 years, whereas the mean duration of method including early replacements was 3.58 years.

\section{Removals}

At the end of 5 years (60 months) 105/197 (53\%) original IUS devices had been removed and $10(5 \%)$ devices were known to have been expelled (five during Year 1, one in Year 2, and two each in Years 3 and 4). The majority of the devices [78 (74\%)] were removed in community SRH clinics, $5(5 \%)$ in a community gynaecology clinic, $12(11 \%)$ in general practice and $10(10 \%)$ in a hospital setting. Of the 10 devices removed in hospital, seven occurred at the time of a gynaecological procedure; hysteroscopy (2), female sterilisation (2), colposcopy (2) and hysterectomy (1). The remaining three devices were removed in gynaecology outpatients: bleeding problem (1), contraception no longer required (1) and unknown (1).

A further 67 removals were documented beyond Year 5: SRH clinic (54), gynaecology clinic (2), general practice (7), under general anaesthetic (2) and at time of hysteroscopy (2). Fifty-one of these devices were known to have been replaced. There was no documented removal for the remaining 15 devices.

\section{Early replacements}

Reasons for the 30 early replacements were as follows: early presentation but at the convenience of the woman (17), replacement post-expulsion (4), return of heavier bleeding (3), replacement postgynaecology procedure (3), miscalculation of expiry date of device (1), possible displaced device (1) and unknown (1).

\section{Number of visits}

At the end of 5 years (60 months) 283 women had made 805 visits to our service, an average of three (range 1-11) visits per woman. Of these visits, 769 (96\%) were with a doctor. The breakdown of visit 


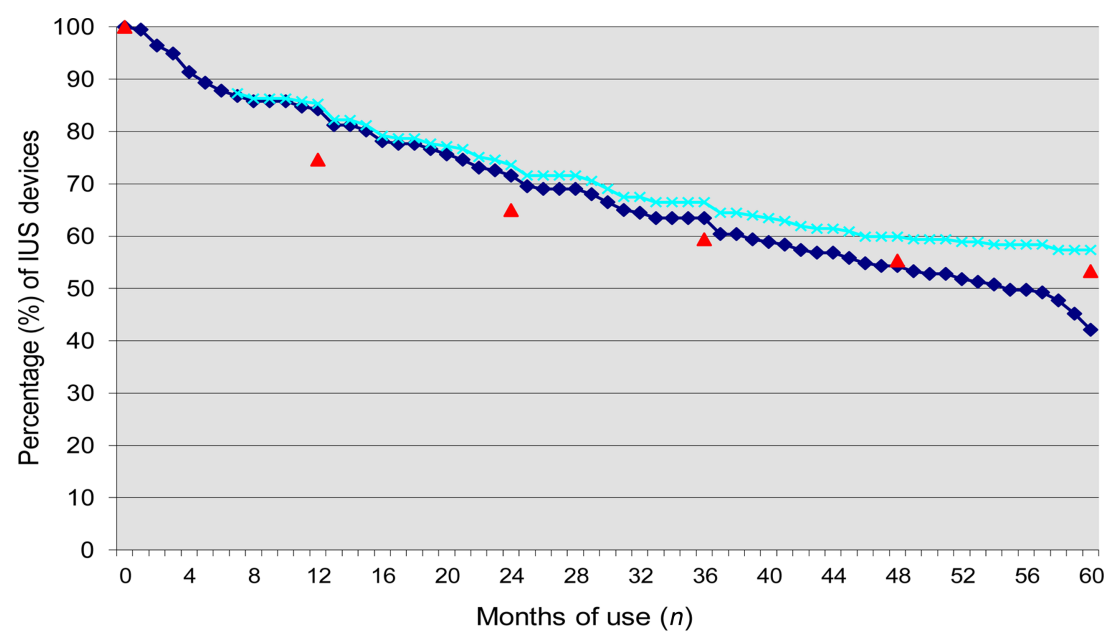

$\ldots$ Original IUS contraceptive devices remaining fitted
$\ldots$ Original IUS contraceptive devices remaining fitted plus early replacements
- IUS contraceptive devices expected to remain fitted (based on NICE economic analysis 2005)

Figure 1 Intrauterine system (IUS) continuation rates compared with National Institute for Health and Clinical Excellence (NICE) predicted rates $(n=197)$.

type was as follows: 170 (21\%) pre-insertion visits (range 0-7), 283 (35\%) insertion visits, 69 (9\%) initial '6-week' follow-up visit, 129 (16\%) asymptomatic follow-up visits often referred to as 'coil check' (range 0-6), 71 (9\%) visits with a problem (range $0-6)$ and $83(10 \%)$ visits for removal of the device.

An additional 66 visits beyond 5 years were also recorded for asymptomatic follow-up (3), IUS problem (7) and IUS removal (56).

IUS problems were reported by $45(16 \%)$ of all women. The majority of problems related to bleeding with or without pain; $80 \%$ of these consultations occurred within the first year. Few women were given additional drugs to manage side effects: metronidazole (9 women), doxycycline (10), norethisterone (2) and Microgynon $30^{\circledR}$ (1). Twenty-five of these women were referred on to a community gynaecology clinic. Reasons for onward referral were bleeding problem and/or pain (10), 'lost threads' (10), for further assessment following abnormal pelvic examination (4) and persistent discharge (1).

\section{Chlamydia tests}

Of the 283 women who had an IUS fitted, 213 (75\%) were tested for chlamydia either prior to or at the time of insertion. Five (2\%) of those tested had a positive result. Three women had two pre-insertion chlamydia tests. A further eight chlamydia tests were documented during the 5-year follow-up as part of investigation of problematic bleeding, two of which were positive.

\section{Costs}

Table 1 lists the actual costs incurred (in British pounds sterling, $£$ ) in providing an IUS for contraception. The equivalent 2012 costs are included for comparison.

The total cost, at the end of 5 years, of providing an IUS for contraception in our SRH service was $£ 49279.04$ The total cost to the end of Year 5 for 197 women for whom complete data were available was $£ 36968.57$, a mean cost of $£ 187.66$ (range $£ 119.17-£ 988.14$, median $£ 158.95$ ) per IUS fitted. The mean duration of use for the 197 in whom we had complete follow up was 3.44 years (41.3 months). Dividing the mean cost by mean duration of use provides a mean annual cost of $£ 54.55$. Table 2 illustrates the breakdown of costs per patient per year and compares these costs with those predicted by NICE. ${ }^{7}$ An additional expenditure of $£ 2621.17$ or $£ 13.31$ per patient occurred beyond Year 5 .

The overall cost of 86 women lost to follow-up was $£ 12310.47$ or $£ 143.15$ (range $£ 118.61-£ 337.60$, median $£ 131.80$ ) per IUS fitted.

\section{DISCUSSION}

This prospective cohort study focuses on the actual cost of providing the IUS for contraception in a UK setting and compares the findings with those modelled theoretically in the UK by NICE in 2005. Costs have been meticulously and comprehensively calculated. There are large numbers of patients with a good (70\%) follow-up rate. We have restricted discussion on costs to the complete cohort only.

Our average continuation rate of 3.44 years is based on those women for whom we had complete follow-up and is close to the 3.32 years predicted by NICE. Our study shows that the cost of providing the IUS is highest in the first year and much less in subsequent years as has been predicted by others. ${ }^{2}{ }^{3}$ Most 
Table 1 Costs (in British pounds sterling, $\mathrm{f}$ ) incurred using an intrauterine system for 5 years (60 months) in a UK-based community contraception and sexual health service

\begin{tabular}{|c|c|c|c|c|}
\hline Description of cost & $\begin{array}{l}\text { Patients: complete data } \\
(n=197)\end{array}$ & $\begin{array}{l}\text { Patients: incomplete data } \\
(n=86)\end{array}$ & $\begin{array}{l}\text { Cost per item } \\
(2005)\end{array}$ & $\begin{array}{l}\text { Cost per item } \\
\text { (2012) }\end{array}$ \\
\hline \multicolumn{5}{|l|}{ Consumables and pharmacy supplies } \\
\hline IUS (initial devices) & 197 & 86 & 85.50 & 76.41 \\
\hline Pre-insertion chlamydia test & $153^{*}$ & $63^{*}$ & 11.20 & 9.40 \\
\hline IUD pack & 197 & 86 & 7.84 & 6.40 \\
\hline Cervical block & 6 & 3 & 0.19 & 0.38 \\
\hline Topical gel and quill & 120 & 57 & 1.19 & 1.27 \\
\hline Dilator & 81 & 32 & 0.56 & 1.38 \\
\hline \multicolumn{5}{|l|}{ Cost of managing problems } \\
\hline Scissors (trimming threads) & 1 & 1 & 2.00 & 2.22 \\
\hline Additional chlamydia swab test & 8 & 0 & 11.20 & 9.40 \\
\hline Additional IUS devices & $5^{*}$ & 3 & 85.50 & 76.41 \\
\hline Metronidazole $400 \mathrm{mg}$ twice daily $\times 14$ & $9^{*}$ & 1 & 0.50 & 1.36 \\
\hline Doxyclycline $100 \mathrm{mg}$ twice daily $\times 14$ & $8^{*}$ & 3 & 1.26 & 1.09 \\
\hline Norethisterone $5 \mathrm{mg} \times 30$ & $2^{*}$ & 1 & 1.25 & 3.86 \\
\hline Microgynon $30^{\circledR}, 3 \times 21$ & 0 & 1 & 2.93 & 1.78 \\
\hline Pregnancy test & 1 & 0 & 0.65 & 0.63 \\
\hline Forceps (removal IUS) & 83 & 0 & 2.90 & 2.29 \\
\hline \multicolumn{5}{|l|}{ Staff time } \\
\hline \multicolumn{5}{|l|}{ Initial consultation } \\
\hline 15 minutes for nurse & 3 & 0 & 5.56 & 6.30 \\
\hline 16 minutes for doctor & 132 & 35 & 11.68 & 13.76 \\
\hline \multicolumn{5}{|l|}{ Insertion } \\
\hline $\begin{array}{l}27 \text { minutes for doctor and } 15 \text { minutes } \\
\text { for nurse }\end{array}$ & 191 & 83 & 25.27 & 29.52 \\
\hline $1 / 8$ consultant clinic & 6 & 3 & 33.24 & 38.59 \\
\hline \multicolumn{5}{|l|}{ Routine, 6-week follow-up visit ('coil check') } \\
\hline 13 minutes for doctor & 55 & 14 & 9.49 & 11.18 \\
\hline \multicolumn{5}{|l|}{ Other follow-up visit ('coil check') } \\
\hline 13 minutes for doctor & $75^{*}$ & $19^{*}$ & 9.49 & 11.18 \\
\hline 13 minutes for nurse & $27^{*}$ & $4^{*}$ & 4.81 & 5.46 \\
\hline $1 / 8$ of consultant sessions & $4^{*}$ & 0 & 33.24 & 38.59 \\
\hline \multicolumn{5}{|l|}{ Follow-up visit with problem } \\
\hline 13 minutes for nurse & 1 & 1 & 4.81 & 5.46 \\
\hline 16 minutes with doctor & $41^{*}$ & $7^{*}$ & 11.68 & 13.76 \\
\hline $1 / 8$ consultant clinic & $15^{*}$ & $6^{*}$ & 33.24 & 38.59 \\
\hline \multicolumn{5}{|l|}{ Removal of device only } \\
\hline 16 minutes for doctor & 55 & 0 & 11.68 & 13.76 \\
\hline $1 / 8$ consultant session & 5 & 0 & 33.24 & 38.59 \\
\hline GP removal & 12 & 0 & 16.62 & 19.26 \\
\hline $\begin{array}{l}\text { Average cost of removing and replacing IUS device in } \\
\text { SRH servicet }\end{array}$ & 27 & 0 & 128.43 & 121.19 \\
\hline \multicolumn{5}{|l|}{ Secondary care costs } \\
\hline Gynaecology outpatient visit & 3 & 0 & 138.00 & 137.00 \\
\hline Hysteroscopy & 2 & 0 & 566.00 & 733.00 \\
\hline General anaesthetic removal & 0 & 0 & 566.00 & 733.00 \\
\hline
\end{tabular}

${ }^{*}$ Numbers refer to number of items rather than number of patients as some patients attended more than once for treatment/follow-up. tIncludes removal and replacement ( $n=23$ ) plus replacement post-expulsion $(n=4)$.

GP, general practitioner; IUD, intrauterine device; IUS, intrauterine system; SRH, sexual and reproductive health.

$(80 \%)$ of the cost is incurred in the first year as this includes the cost of supplying and fitting the device, and for $31 \%$ of women that was all that was needed.
However, the longer the woman retains the device, the more cost effective it becomes. Even at the end of the first year of use, our mean cost $(£ 150.61$ per 
Table 2 Cost (in British pounds sterling, $\mathrm{f}$ ) of providing the intrauterine system for contraception per patient per year

\begin{tabular}{|c|c|c|c|c|c|c|c|c|}
\hline \multirow[b]{2}{*}{ Sample profile } & \multicolumn{6}{|c|}{ Cost $(\mathbf{f})$ for stated time period } & \multirow{2}{*}{$\begin{array}{l}\text { Average } \\
\text { duration } \\
\text { (years) }\end{array}$} & \multirow{2}{*}{$\begin{array}{l}\text { Average } \\
\text { annual } \\
\text { cost (f) }\end{array}$} \\
\hline & $\begin{array}{l}0-12 \\
\text { months }\end{array}$ & $\begin{array}{l}\text { 12-24 } \\
\text { months }\end{array}$ & $\begin{array}{l}\text { 24-36 } \\
\text { months }\end{array}$ & $\begin{array}{l}36-48 \\
\text { months }\end{array}$ & $\begin{array}{l}48-60 \\
\text { months }\end{array}$ & $\begin{array}{l}0-60 \\
\text { months }\end{array}$ & & \\
\hline $\begin{array}{l}\text { Complete data } \\
(n=197)\end{array}$ & 150.61 & 6.75 & 6.53 & 7.94 & 15.83 & 187.66 & 3.44 & 54.55 \\
\hline $\begin{array}{l}\text { Incomplete data } \\
(n=86)\end{array}$ & 140.63 & 0.99 & 1.30 & 0.11 & 0.11 & 143.14 & 3.44 & 41.61 \\
\hline Total $(n=283)$ & 147.83 & 5.32 & 5.57 & 5.25 & 11.46 & 175.43 & 3.44 & 51.00 \\
\hline NICE prediction & 206.64 & 0.00 & 0.00 & 0.00 & 27.40 & 234.04 & 3.32 & 70.49 \\
\hline
\end{tabular}

NICE, National Institute for Health and Clinical Excellence.

woman) is less than the mean cost of providing the combined oral contraceptive pill ( $£ 177.56)$ during the same years in our service, this being calculated using the same methodology as this study. ${ }^{21}$ In keeping with NICE, we have calculated mean costs to 5 years (60 months); however, we have follow-up data indicating that $17 / 197(9 \%)$ of women chose to retain their device beyond 6 years.

Uniquely, we have shown that the number of women returning for the management of problems is small, and the cost of managing these problems is inexpensive.

Also uniquely, we have shown that a significant $(15 \%)$ number of women had their devices replaced before 5 years, a finding that has not been predicted by others. A small number of these replacements were unavoidable (e.g. replacement post-expulsion or after a gynaecological procedure), however the majority were for the woman's convenience. A small number of replacements were because of the return of heavier bleeding, for which there is no evidence that early replacement is effective.

At $£ 54.55$, our cost per year for providing IUS for contraception is $23 \%$ lower than that predicted by NICE, namely $£ 70.49$ per year. $^{7}$ Our main saving was due to our patients having fewer overall visits than predicted by NICE and lower staff costs. NICE allowed for four visits with a general practitioner (GP): an initial visit, a separate visit for insertion, a check-up and a removal visit for every woman. The mean number of visits in our study was three per woman. Most of our doctors are NCCDs who are considerably cheaper to employ than GPs as allowed for in NICE's calculation. Our equipment was also slightly cheaper than that allowed for by NICE (£96.24 vs. $£ 106.36$ per woman for the insertion pack, IUS device and forceps for removal). Conversely, NICE made no allowance for chlamydia testing ( $£ 8.55$ per woman) management of problems ( $£ 1.93$ per woman) or secondary care costs $(£ 14.37$ per woman). In addition, NICE predicted 57 minutes of general practice time over 3.32 years, a mean annual time of 17.17 minutes. In our service the actual mean doctor time was 71 minutes over
3.44 years, a mean annual time of 20.77 minutes ('Mapping the Patient Pathway', unpublished data, Gwent Sexual and Reproductive Health, 2006). So although our staff costs were lower, consultation times were longer than those calculated by NICE.

Although the IUS has a 5-year (60-month) licence for contraception, we have shown that some women attend for replacement at a time that is convenient for them rather than at the end of the 5 years. As we have looked at the actual costs incurred each year, we included the mean insertion cost of an IUS (£128.43) for every replacement regardless of how near the end of the 5 years the device was replaced. Therefore the costs in the fifth year were higher than expected. However, these additional costs are to a great extent offset by those women choosing to continue into and beyond 6 years of use (i.e. off-licence use), which would have resulted in a reduction in cost for the first year of the new cycle.

Applying 2012 costs to our patient pathway of 2005 for the complete cohort lowered the overall cost at the end 5 years by $1.4 \%$ and the annual cost of providing the IUS from $£ 54.55$.to $£ 52.59$ Although staff costs have risen, the actual cost of the IUS device and consumables has dropped as a result of a buying contract.

Indeed, we would expect the actual annual cost of providing the IUS to have fallen further since 2005 as since the study was undertaken we have streamlined service delivery to reduce the need for repeated visits. We now aim to combine a pre-insertion discussion with the IUS fitting in one visit whenever possible. We also now make it easier for patients to identify which clinics have a doctor present $(50 \%$ of all clinics) where IUSs can be fitted so women are less likely to have to make a separate pre-insertion visit. Routine testing for chlamydia has been replaced by a formal risk assessment for sexually transmitted infection and this has led to a reduction in the number of chlamydia tests performed. In addition, we test for chlamydia and provide prophylactic treatment, for asymptomatic women whom we have assessed as being at higher risk of infection, at the time of IUS fitting. Now, unprotected sex in the current cycle would be our main 
reason for not fitting an IUS on the first visit. All doctors are now trained to provide a cervical block which, although not formally evaluated, might be expected to reduce the number of women referred on to community gynaecology clinic for problems with IUS fitting. In addition, in line with Faculty of Sexual $\&$ Reproductive Healthcare guidance we no longer offer routine 'coil checks'. ${ }^{22}$ Instead we advise women how to check their own threads and only to return to us if they have problems or cannot feel their threads. In 2012, patients can see a nurse for routine removal of their IUS, whereas previously this would entail a doctor visit. Also, in line with other services in the UK, we now have two nurses who are trained to fit IUDs, which it is anticipated will reduce costs further.

Uncertainties lie in the $30 \%$ of patients in the incomplete data cohort that were lost to follow-up, and how they might differ from those who remained in the study. We used these patients for calculating costs, since where we did have the data, greater numbers make the figures more robust. If a high number of these women had had their device removed early, or had gynaecological procedures arising from complications, then continuation rates would be lower and the overall cost of using the device would be higher than our calculated figure. Conversely, if most of these women continued using the device without problems or the need to access health services, continuation rates would be higher and the overall cost would be cheaper. As patients with problems would have been likely to access the service or their GP, thus generating identifiable records, we consider that the latter scenario is more likely.

The present study was not designed to address cost effectiveness nor compare costs with other long-acting or permanent methods of contraception. It was not designed by 'intention to treat', and women who had the IUS removed were no longer included in the analysis. We do not know the ongoing costs for women who were dissatisfied with the method compared with those women who retained the device for the whole 5 years. Women who switch between different contraceptive methods may be more vulnerable to pregnancy, and this could therefore underestimate the costs for women who initially choose the IUS, but then go on to use a less effective method. Conversely, we do not know the costs saved by the gynaecological benefits (e.g. relief from premenstrual syndrome, dysmenorrhoea or menorrhagia) conferred by the IUS, which are considerable. ${ }^{1}$ We did not allow for the costs saved by pregnancies being averted, although this has been calculated as approximately four pregnancies. ${ }^{3}$ While contraception evidently saves money, services providing them are unlikely to be those realising the savings.

\section{CONCLUSIONS}

The cost of providing the IUS for contraception was calculated to be $23 \%$ lower in the present study than that predicted by NICE, and was less than the cost of providing the combined oral contraceptive pill in our service. Fitting IUSs in community clinics is probably cheaper than doing so in primary care. Streamlining the patient pathway will reduce costs further. Restricting access to the IUS because of its initial cost is a false economy.

Acknowledgements The authors would like to thank Professor Ceri Phillips, Health Economist at Swansea University, for his comments and advice.

Competing interests Louise Cook has received honoraria from Bayer Healthcare for teaching engagements.

Provenance and peer review Not commissioned; externally peer reviewed.

Data sharing statement Original data files can be made freely available to anyone who wishes to see them. Requests can be made by e-mail to the corresponding author.

\section{REFERENCES}

1 Sonnenberg SA, Burkman RT, Hagerty CG, et al. Costs and net health effects of contraceptive methods. Contraception 2004;69:447-459.

2 Chiou CF, Trussell J, Reyes E, et al. Economic analysis of contraceptives for women. Contraception 2003;68:3-10.

3 Trussell J, Joseph A, Levique MD, et al. The economic value of contraception: a comparison of 15 methods. Am J Public Health $1995 ; 85: 494-503$.

4 French RS, Cowan FM, Mansour DJA, et al. Implantable contraceptives (subdermal implants and hormonally impregnated intrauterine systems) versus other forms of reversible contraceptives: two systematic reviews to assess relative effectiveness, acceptability, tolerability and cost-effectiveness. Health Technol Assess 2000;4(7).

5 Varney S, Guest J. Relative cost effectiveness of Depo-Provera, Implanon, and Mirena in reversible long-term hormonal contraception in the UK. Pharmacoeconomics 2004;22:1141-1151.

6 Backman T. Benefit-risk assessment of the levonorgestrel intrauterine system in contraception. Drug Saf 2004;27:1185-1204.

7 National Institute for Health and Clinical Excellence (NICE). National Cost Impact Report: Implementing the NICE Guideline on Long-Acting Reversible Contraception. December 2005. http://www.nice.org.uk/nicemedia/live/10974/29916/ 29916.pdf [accessed 18 March 2012].

8 Armstrong N, Davey C, Donaldson C. The Economics of Sexual Health: Findings. London, UK: fpa, 2005.

9 National Institute for Health and Clinical Excellence. Long-Acting Reversible Contraception (Clinical Guideline CG30). October 2005. http://www.nice.org.uk/Guidance/ CG30/Guidance/pdf/English [accessed 18 March 2012].

10 The National Assembly for Wales. A Strategic Framework for Promoting Sexual Health in Wales. Better Health - Better Wales. http://www.wales.nhs.uk/sites3/Documents/568/ WAGStrategicFramework.pdf [accessed 18 March 2012].

11 Department of Health. Better Prevention, Better Services, Better Sexual Health - The National Strategy for Sexual Health and HIV. 27 July 2001. http://www.dh.gov.uk/prod_consum_dh/ groups/dh_digitalassets/@dh/@en/documents/digitalasset/ dh_4058945.pdf [accessed 18 March 2012].

12 Welsh Assembly Government. Sexual Health and Wellbeing Action Plan for Wales 2010-2015. November 2010. http:// 
www.shnwales.org.uk/Documents/485/Strategy\%20\%28English \%29.pdf [accessed 18 March 2012].

13 National Institute for Health and Clinical Excellence. Implementation Uptake Report: Long Acting Reversible Contraception (LARC). 2010. http://www.nice.org.uk/media/67F/ C5/UptakeReportCG30LARC.pdf [accessed 29 November 2012].

14 National Institute for Health and Clinical Excellence. Assumptions Used in Estimating a Population Benchmark. 2012. http://www. nice.org.uk/usingguidance/commissioningguides/iud/ assumptionsiud/jsp [accessed 30 August 2012].

15 Kishen M, Belfield T. Contraception in crisis. J Fam Plann Reprod Health Care 2006;32:211-212.

16 Backman T, Huhtala S, Blom T, et al. Length of use and symptoms associated with premature removal of the levonorgestrel intrauterine system: a nation-wide study of 17,360 users. BJOG 2000;107:335-339.

17 National Assembly for Wales. SDR 138/2005. First Release. NHS Community Contraceptive Services in Wales, 2004-2005. http://wales.gov.uk/docs/statistics/2005/051215sdr1382005en. pdf [accessed 18 March 2012].
18 Department of Health. Findings of the Baseline Review of Contraceptive Services in England. 2007. http://www.dh.gov.uk/en/ Publicationsandstatistics/Publications/Publications PolicyAndGuidance/DH_074727 [accessed 18 March 2012].

19 Department of Health. Payment by Results National Tariff 2005-06. http://collections.europarchive.org/tna/ 20100509080731/http://dh.gov.uk/prod_consum_dh/groups/ dh_digitalassets/@dh/@en/documents/digitalasset/dh_4091532. xls [accessed 12 April 2012].

20 Department of Health. Payment by Results National Tariff 2011-12. http://data.gov.uk/dataset/payment-by-results-201011-national-tariff-information [accessed 12 April 2012].

21 Lipetz C, Phillips C, Fleming C. The cost-effectiveness of a long-acting reversible contraceptive (Implanon ${ }^{\circledR}$ ) relative to oral contraception in a community setting. Contraception 2009;79:304-309.

22 Faculty of Sexual and Reproductive Healthcare Clinical Effectiveness Committee. Intrauterine Contraception. November 2007. http://www.fsrh.org/pdfs/CEUGuidanceIntrauterine ContraceptionNov07.pdf [accessed 18 March 2012]. 